\title{
O Ensino de Botânica na Educação Básica - Reflexos na aprendizagem dos alunos
}

\author{
Botanics Teaching in Basic Education - Reflections in student learning \\ La Enseñanza de la Botánica en la Educación Básica - Reflejos en el aprendizaje de los alunos
}

Recebido: 12/07/2021 | Revisado: 19/07/2021 | Aceito: 21/07/2021 | Publicado: 28/07/2021

\author{
Raquel Silva Cotrim Carvalho \\ ORCID: https://orcid.org/0000-0002-7362-7723 \\ Universidade Estadual de Goiás, Brasil \\ E-mail: raquelcotrimbio@gmail.com \\ Sabrina do Couto de Miranda \\ ORCID: https://orcid.org/0000-0002-3861-6674 \\ Universidade Estadual de Goiás, Brasil \\ E-mail: sabrinac.miranda@gmail.com \\ Plauto Simão De-Carvalho \\ ORCID: https://orcid.org/0000-0002-5467-5754 \\ Universidade Estadual de Goiás, Brasil \\ E-mail: plauto.decarvalho@gmail.com
}

\begin{abstract}
Resumo
Atualmente percebe-se uma negligência em relação ao ensino de plantas. $\mathrm{O}$ ensino de botânica tem sido trabalhado de forma tradicional e memorística o que tem dificultado, cada vez mais, a aprendizagem dos alunos sobre as plantas, intensificando consequentemente a cegueira botânica. Tanto alunos quanto professores apresentam uma aversão aos conteúdos de botânica, tornando o processo ensino-aprendizagem mais difícil que o habitual. O presente trabalho visa analisar, através de uma revisão sistemática da literatura, o processo de ensino-aprendizagem em botânica na Educação Básica, bem como analisar a influência da utilização de diferentes metodologias na aprendizagem dos alunos. A análise dos trabalhos selecionados evidenciou que a utilização de metodologias diferenciadas, que fogem do tradicional, aumenta o engajamento e o interesse dos alunos em relação à botânica, além de facilitar a aquisição e compreensão de conhecimentos botânicos. Considera-se que a mudança no processo de ensino da Botânica pode refletir positivamente na aprendizagem dos alunos.
\end{abstract}

Palavras -chave: Plantas; Ensino-aprendizagem; Escola.

\begin{abstract}
Currently, there is a negligence in relation to the teaching of plants. The teaching of botany has been worked in a traditional and memoristic way, which has increasingly hindered the students' learning about plants, consequently intensifying botanic blindness. Both students and teachers have an aversion to the contents of botany, making the teaching-learning process more difficult than usual. The present work aims to analyze, through a systematic review of the literature, the teaching-learning process of botany in Basic Education, as well as to analyze the influence of the use of different methodologies on the students' learning. The analysis of the selected papers showed that the use of differentiated methodologies, which are not traditional, increases the students' engagement and interest in botany, besides facilitating the acquisition and understanding of botanical knowledge. It is considered that the change in the teaching process of Botany can reflect positively on the students learning.
\end{abstract}

Keywords: Plants; Teaching-learning; School.

\section{Resumen}

Actualmente, se percibe una negligencia en relación con la enseñanza de las plantas. La enseñanza de la botánica se ha trabajado de forma tradicional y memorística, lo que ha dificultado cada vez más el aprendizaje de los alumnos sobre las plantas, intensificando en consecuencia la ceguera botánica. Tanto los alumnos como los profesores tienen aversión a los contenidos de botánica, lo que hace que el proceso de enseñanza-aprendizaje sea más difícil de lo habitual. El presente trabajo pretende analizar, a través de una revisión bibliográfica sistemática, el proceso de enseñanza-aprendizaje de la botánica en la Educación Básica, así como analizar la influencia del uso de diferentes metodologías en el aprendizaje de los alumnos. El análisis de los trabajos seleccionados mostró que el uso de metodologías diferenciadas que no siguen el enfoque tradicional aumenta el compromiso y el interés de los estudiantes por la botánica, además de facilitar la adquisición y comprensión de los conocimientos botánicos. Se considera que el cambio en el proceso de enseñanza de la Botánica puede repercutir positivamente en el aprendizaje de los alumnos.

Palabras clave: Plantas; Enseñanza-aprendizaje; Escuela. 


\section{Introdução}

Mundialmente, o Brasil é um dos países mais importantes em termos de biodiversidade de plantas. No domínio geopolítico da nação brasileira temos seis diferentes biomas, dentre eles os mais ricos em espécies de plantas são: Floresta Amazônica, Floresta Atlântica e Cerrado, estes dois últimos classificados como áreas altamente biodiversas e ameaçadas pela degradação antrópica (Bicalho \& Miranda, 2015). Por outro lado, temos notórias dificuldades relacionadas ao ensino de botânica na Educação Básica brasileira. Tais dados suscitam um questionamento: Como isso é possível?

A educação ambiental e a preocupação com o meio ambiente têm sido temáticas em destaque nos cursos de formação para professores, em palestras e projetos que trabalham a formação integral do estudante na escola. Embora a educação ambiental seja um tema transversal na educação básica (Brasil, 1997); ainda é perceptível o desinteresse e descaso dos alunos em relação a compreensão de qualquer conteúdo que se relacione com a botânica e sua importância, por exemplo.

Ao se fazer uma análise de como a botânica tem sido trabalhada e de como os alunos têm recebido esses conhecimentos, nota-se alguns pontos que necessitam de maior atenção, como: a falta de relação do conteúdo ministrado em sala de aula com a realidade, falta de interesse dos alunos e dificuldades dos professores que, na maioria das vezes, não dominam o conteúdo ou trabalham a botânica de forma superficial, metódica e conteudista (Santos \& Lemos, 2016; Araújo \& Lemos, 2016; Ramos \& Silva, 2013; Silva \& Cavassan, 2005). Esses pontos, com certeza, contribuem para o agravamento da cegueira botânica entre os alunos.

Katon, Towata e Saito (2013) contextualizam que Wandersee e Schussler definiram o termo cegueira botânica para descrever o desinteresse das pessoas em relação aos vegetais. Os mesmos autores pontuam que esse desinteresse pode causar uma visão equivocada em relação à importância dos seres vivos, colocando as plantas como inferiores aos animais. Percebe-se que a maioria das pessoas não reconhece as plantas como parte integrante e importante para a vida. Muitas vezes o processo de construção da cegueira botânica se inicia na escola.

Observa-se professores com dificuldades no domínio do conteúdo sobre plantas, alguns com rejeição sendo esta transmitida diretamente ou indiretamente aos alunos. Muitos professores de biologia já se depararam com uma sala de aula onde a maioria dos estudantes afirmava gostar de zoologia ou biologia celular e, em último caso, da botânica. Provavelmente, o problema se inicie na Educação Infantil e primeiras séries do Ensino Fundamental, onde o professor, geralmente da área de Pedagogia, normalmente não trabalha de forma significativa o tema "Plantas" com os estudantes.

Salatino e Buckeridge (2016) discutem que vivemos em um ciclo vicioso, os professores com formações insatisfatórias, os alunos seguirão todas as etapas educacionais apresentando aversão à botânica e os que se tornarem professores, no futuro, não terão capacidade de formar alunos isentos da cegueira botânica. É esse ciclo que presenciamos na educação básica, os alunos não se interessam e os professores, mediante as dificuldades (Santos \& Lemos (2016), acabam por utilizar as metodologias tradicionais e decorativas para a transmissão de conhecimentos botânicos.

Ao se observar a forma como o ensino de botânica está sendo conduzido, pode-se questionar: Quais seriam as metodologias mais eficientes para o ensino-aprendizagem de botânica? Quais metodologias podem despertar maior interesse e participação dos alunos? Quais seriam os resultados na aprendizagem, uma vez que no contexto atual há desinteresse dos alunos em aprender botânica? Assim, com base em trabalhos publicados na literatura, o presente artigo visa analisar o processo ensino-aprendizagem de botânica na Educação Básica.

\section{Metodologia}

Para identificarmos de que forma o ensino de botânica tem sido trabalhado na Educação Básica foi realizada uma revisão sistemática da literatura. Segundo Galvão, Pansani e Harrad (2015, p. 335) trata-se de um método utilizado para 
"selecionar e avaliar criticamente pesquisas relevantes", podendo haver análises dos dados presentes nos estudos, os quais farão parte da revisão.

O caminho metodológico percorrido se baseou em Galvão e Pereira (2014), com adaptações:

I) elaboração da(s) pergunta(s) de pesquisa;

II) busca nas plataformas: Portal de Periódicos da Capes (Coordenação de Aperfeiçoamento de Pessoal de Nível Superior) (https://www.periodicos.capes.gov.br) e Plataforma de teses e dissertações da Capes (https://catalogodeteses. capes.gov.br/catalogo-teses);

III) seleção dos artigos, evidenciando a forma de inclusão e exclusão dos trabalhos na pesquisa, discutida a seguir;

IV) extração e síntese dos dados, os quais foram organizados em uma planilha do Excel contendo as seguintes informações: autor(es), ano da publicação, público-alvo, temática, as metodologias utilizadas e os principais resultados;

V) análise e discussão dos dados extraídos obtendo os resultados da pesquisa.

Para a busca nas plataformas de pesquisa utilizou-se as seguintes palavras: botânica, ensino e aprendizagem. As palavras foram colocadas nas plataformas de busca sem vírgula, sendo separadas apenas por um espaço. Para a análise e seleção dos artigos no Portal de Periódicos da Capes nenhum recorte temporal foi feito. Na plataforma de teses e dissertações foi feito um recorte temporal entre 2015 a 2019, para obtenção de dados mais recentes sobre o ensino de botânica na educação básica.

À princípio a análise foi feita através do título, resumo e palavras-chave dos trabalhos, sendo selecionados os que atendiam às demandas da pesquisa, dentro do ensino de botânica (Quadro 1). É necessário evidenciar que na plataforma de teses e dissertações da Capes a análise centrou nos 3 mil primeiros trabalhos obtidos devido a um erro. Ao chegar em um determinado estágio da pesquisa, a plataforma apresentou informação de erro e voltou ao início da busca. Assim, optamos por delimitar a análise nesse conjunto de trabalhos.

Durante a triagem dos trabalhos obtidos, vários trabalhos foram excluídos uma vez que se relacionavam ao ensino de botânica no ensino superior ou remetiam à formação de professores, não se enquadravam no foco da pesquisa. No caso de artigos provenientes de dissertação ou tese já selecionadas, a preferência foi pela seleção/leitura das dissertações ou teses, por apresentarem maior detalhamento de dados. Ao final, 19 trabalhos constituiu o corpus da pesquisa (Quadro 1) e utilizou-se uma planilha no Excel para organizar os dados extraídos.

Quadro 1: Detalhamento dos números de trabalhos selecionados e analisados na revisão sistemática da literatura sobre Ensino de Botânica na Educação Básica.

\begin{tabular}{|l|c|c|}
\hline & Portal de Periódicos da Capes & $\begin{array}{l}\text { Plataforma de teses e dissertações da } \\
\text { Capes }\end{array}$ \\
\hline $\begin{array}{l}\text { Número de trabalhos disponíveis nas } \\
\text { plataformas de busca através das palavras- } \\
\text { chave }\end{array}$ & 69 & 157.570 \\
\hline $\begin{array}{l}\text { Número de trabalhos após recorte temporal } \\
\text { 2015-2019 }\end{array}$ & Não houve recorte temporal & 61.743 \\
\hline Número de trabalhos analisados & 69 & 3.000 \\
\hline $\begin{array}{l}\text { Número de trabalhos selecionados por análise } \\
\text { de título e resumo }\end{array}$ & 15 & 24 \\
\hline $\begin{array}{l}\text { Número de trabalhos selecionados após filtrar } \\
\text { pelo critério de inclusão/exclusão }\end{array}$ & 9 & 10 \\
\hline Seleção final da busca & & 19 \\
\hline
\end{tabular}

Fonte: Elaboração própria. 


\section{Resultados}

Os trabalhos analisados são publicações entre os anos de 2007 e 2019, concentrando-se após 2013 (16 trabalhos). A investigação revelou uma maior preocupação em investigar o ensino de botânica nos anos finais do ensino fundamental e ensino médio (Figura 1). Apenas um trabalho abordou os anos iniciais do ensino fundamental (Figura 1). É importante ressaltar que a maioria das pesquisas foi conduzida em turmas de $7^{\circ}$ ano do ensino fundamental II e $2^{a}$ série do ensino médio. No quadro abaixo (Quadro 2) pode-se observar os trabalhos analisados através da revisão sistemática da literatura, descritos o nome do autor, o ano de referência bem como o título do trabalho analisado. Abaixo do quadro, observa-se a Figura 1, a qual descreve a quantidade de trabalhos analisados por modalidade de ensino na Educação Básica.

Quadro 2: Trabalhos sobre o Ensino de Botânica na Educação Básica selecionados para análise por meio de revisão sistemática da literatura, organizados em ordem alfabética.

\begin{tabular}{|c|c|c|}
\hline \multicolumn{2}{|c|}{ Referências } & \multirow{2}{*}{$\begin{array}{l}\text { Títulos dos trabalhos } \\
\text { Contribuições da exposição "descobrindo os segredos das flores do lavrado" } \\
\text { como organizador prévio no ensino do conceito de flor }\end{array}$} \\
\hline 01 & Anjos (2016) & \\
\hline 02 & Bini (2019) & A horta orgânica como ferramenta no ensino de botânica \\
\hline 03 & Brito (2009) & Caça ao tesouro: uma aprendizagem pela descoberta \\
\hline 04 & Carneiro (2019) & $\begin{array}{l}\mathrm{O} \text { ensino-aprendizagem de botânica a partir de metodologias ativas com o } \\
\text { uso de tecnologias digitais }\end{array}$ \\
\hline 05 & Carvalho (2017) & $\begin{array}{l}\text { Botânica no Ensino Fundamental II: aplicação de conceitos do movimento } \\
\text { CTS por meio de metodologia ativa }\end{array}$ \\
\hline 06 & Costa, Duarte e Gama (2019) & A gamificação da botânica: uma estratégia para a cura da "cegueira botânica" \\
\hline 07 & Inada (2016) & $\begin{array}{l}\text { Ensino de botânica mediado por recursos multimídia: as contribuições de um } \\
\text { software de autoria para o ensino dos ciclos reprodutivos dos grupos vegetais }\end{array}$ \\
\hline 08 & Kull (2018) & $\begin{array}{l}\text { Problematizar situações de ensino e desenvolver habilidades cognitivas: } \\
\text { estudo sobre a importância das folhas para a planta e o ambiente }\end{array}$ \\
\hline 09 & Lazzari et al. (2017) & Trilha ecológica: um recurso pedagógico no ensino da Botânica \\
\hline 10 & Matos et al. (2015) & $\begin{array}{l}\text { Recursos didáticos para o ensino de botânica: uma avaliação das produções } \\
\text { de estudantes em universidade sergipana }\end{array}$ \\
\hline 11 & Moul e Silva (2017) & $\begin{array}{l}\text { A construção de conceitos em botânica a partir de uma sequência didática } \\
\text { interativa: proposições para o ensino de Ciências }\end{array}$ \\
\hline 12 & Navarro et al. (2007) & $\begin{array}{l}\text { Utilização de plantas medicinais e aromaterapia como ferramenta no ensino } \\
\text { fundamental das ciências }\end{array}$ \\
\hline 13 & Rodrigues (2019) & $\begin{array}{l}\text { Coleções botânicas e suas contribuições para o ensino de sistemática e } \\
\text { morfologia vegetal no ensino médio }\end{array}$ \\
\hline 14 & Salomão (2016) & $\begin{array}{l}\text { Horta escolar: temas geradores e os momentos pedagógicos no ensino de } \\
\text { ciências }\end{array}$ \\
\hline 15 & Santana e Oliveira (2009) & $\begin{array}{l}\text { Processo de inserção dos mapas conceituais, como recurso didático, no } \\
\text { ensino de biologia }\end{array}$ \\
\hline 16 & Santos (2015) & $\begin{array}{l}\text { O ensino de grupos vegetais em diferentes espaços educativos para a } \\
\text { promoção da aprendizagem significativa }\end{array}$ \\
\hline 17 & $\begin{array}{l}\text { Serra, Freitas e Lira-da-Silva } \\
\text { (2013) }\end{array}$ & O jogo como ferramenta didática para o ensino de botânica \\
\hline 18 & Souza (2015) & Botânica no cotidiano: experiências vivenciadas por alunos do ensino médio \\
\hline 19 & Stanski et al. (2016) & $\begin{array}{l}\text { Ensino de Botânica no Ensino Fundamental: estudando o pólen por meio de } \\
\text { multimodos }\end{array}$ \\
\hline
\end{tabular}

Fonte: Elaboração própria. 
Figura 1: Trabalhos relacionados ao Ensino de Botânica na Educação Básica distribuídos por nível de ensino.

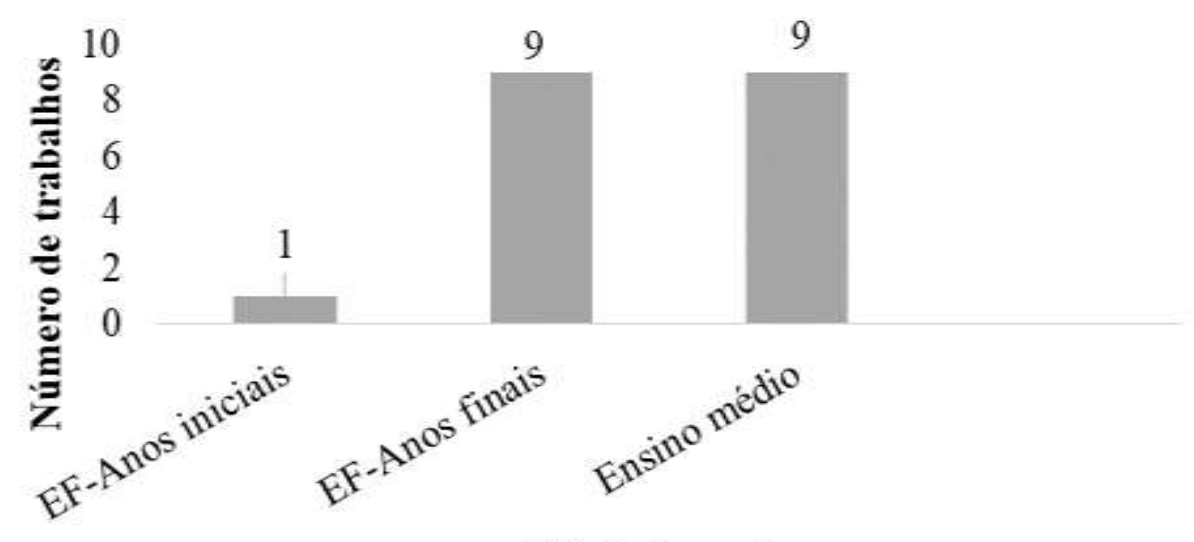

Nível de ensino

Fonte: Elaboração própria.

Os estudos analisados apresentaram várias possibilidades de estratégias metodológicas para se trabalhar a botânica em sala de aula (Tabela 1). É importante ressaltar que em um mesmo estudo os autores podem ter utilizado mais de uma estratégia. As metodologias mais utilizadas foram os jogos interativos e didáticos, e as aulas práticas (Tabela 1).

A compilação dos resultados apresentados pelos trabalhos, que utilizaram atividades diferenciadas para o ensino de botânica, mostrou dados interessantes (Tabela 2). A maioria (68,5\% dos trabalhos) ressaltou que tais metodologias melhoram a participação, engajamento e aumentam a motivação e interesse dos alunos pelas aulas (Tabela 2). Decorrente disso, tem-se altos percentuais relacionados à melhor compreensão de conceitos botânicos (58\%), aprendizagem com mais significado (53\%) e aulas mais atrativas, dinâmicas e prazerosas (37\%).

Dentre os resultados sumarizados (Tabela 2), baixos percentuais foram associados ao estímulo à curiosidade, conexão da botânica com a realidade do aluno e protagonismo estudantil (Tabela 2). Aspectos importantes que também precisam ser priorizados nas atividades trabalhadas em sala de aula. 
Tabela 1: Metodologias utilizadas no Ensino de Botânica na Educação Básica com base em trabalhos publicados na literatura.

\begin{tabular}{|c|c|c|}
\hline Metodologia utilizada & $\begin{array}{c}\text { Abordagem nos } \\
\text { trabalhos selecionados }\end{array}$ & Referências \\
\hline Jogos interativos e didáticos & $42,0 \%$ & $\begin{array}{c}(1) ;(3) ;(5) ;(6) ; \\
(10) ;(11) ;(17) ;(18)\end{array}$ \\
\hline $\begin{array}{l}\text { Aulas práticas } \\
\text { (em laboratório e em sala) }\end{array}$ & $42,0 \%$ & $\begin{array}{c}(1) ;(2) ;(10) ;(11) ;(12) ;(13) ; \\
(14) ;(19)\end{array}$ \\
\hline $\begin{array}{l}\text { Aulas de campo } \\
\text { (visitas em jardins, praças, entorno escola) }\end{array}$ & $37,0 \%$ & $\begin{array}{c}(2) ;(3) ;(8) ;(13) ;(10) ;(16) ; \\
(18)\end{array}$ \\
\hline $\begin{array}{l}\text { Vídeos } \\
\text { (documentários, videoaulas, animações e produção) }\end{array}$ & $31,5 \%$ & (1), (4); (8); (11); (14); (18) \\
\hline Construção de mapa conceitual & $26,3 \%$ & (2); (5); (15); (16); (19) \\
\hline $\begin{array}{l}\text { Construção e utilização de exsicatas e modelos } \\
\text { didáticos }\end{array}$ & $26,3 \%$ & (2); (11); (13); (16); (19) \\
\hline Exposições e Feira de ciências & $21,0 \%$ & $(1) ;(5) ;(14) ;(18)$ \\
\hline Registros fotográficas & $16,0 \%$ & $(5) ;(8) ;(18)$ \\
\hline Construção e cultivo de plantas (horta escolar) & $10,5 \%$ & $(12) ;(14)$ \\
\hline Desenhos & $10,5 \%$ & $(10) ;(16)$ \\
\hline Utilização de software (site/blog/website) & $10,5 \%$ & $(7) ;(18)$ \\
\hline Apresentação com Slides & $10,5 \%$ & $(4) ;(14)$ \\
\hline Montagem de herbário & $5,0 \%$ & (5) \\
\hline Trilha ecológica & $5,0 \%$ & (9) \\
\hline
\end{tabular}

Fonte: Elaboração própria. Referências: (1) Anjos (2016), (2) Bini (2019), (3) Brito (2009), (4) Carneiro (2019), (5) Carvalho (2017), (6) Costa, Duarte e Gama (2019), (7) Inada (2016), (8) Kull (2018), (9) Lazzari et al. (2017), (10) Matos et al. (2015), (11) Moul e Silva (2017), (12) Navarro et al. (2007), (13) Rodrigues (2019), (14) Salomão (2016), (15) Santana e Oliveira (2009), (16) Santos (2015), (17) Serra, Freitas e Lira-da-Silva (2013), (18) Souza (2015), (19) Stanski et al. (2016).

Tabela 2: Principais resultados obtidos por meio da aplicação de metodologias diferenciadas por trabalhos publicados na literatura voltados ao Ensino de Botânica na Educação Básica.

\begin{tabular}{l|c|c}
\hline \multicolumn{1}{c|}{ Principais resultados } & $\begin{array}{c}\text { Abordagem nos trabalhos } \\
\text { selecionados }\end{array}$ & Referências \\
\hline $\begin{array}{l}\text { Melhoria na participação/engajamento/ } \\
\text { motivação e interesse dos alunos }\end{array}$ & $68,5 \%$ & $(1) ;(2) ;(3) ;(4) ;(5) ;(8) ;(9) ;(10) ;$ \\
$\begin{array}{l}\text { Evolução e compreensão de conceitos } \\
\text { botânicos }\end{array}$ & $58,0 \%$ & $(12) ;(13) ;(17) ;(18) ;(19) ;(6) ;(7) ;(9) ;(10) ;(11) ;$ \\
$\begin{array}{l}\text { Aprendizagem com mais significado } \\
\text { Aulas mais atrativas, dinâmicas e }\end{array}$ & $53,0 \%$ & $(13) ;(14) ;(15) ;(17) ;$ \\
prazerosas & & $(3) ;(5) ;(8) ;(10) ;(13) ;(14) ;$ \\
$\begin{array}{l}\text { Estímulo à curiosidade } \\
\text { Conexão da botânica com a realidade }\end{array}$ & $37,0 \%$ & $(1) ;(4) ;(6) ;(7) ;(10) ;(13) ;(18)$ \\
Protagonismo estudantil & $16,0 \%$ & $(4) ;(5) ;(17)$ \\
\end{tabular}

Fonte: Elaboração própria. Referências: (1) Anjos (2016), (2) Bini (2019), (3) Brito (2009), (4) Carneiro (2019), (5) Carvalho (2017), (6) Costa, Duarte e Gama(2019), (7) Inada (2016), (8) Kull (2018), (9) Lazzari et al. (2017), (10) Matos et al. (2015), (11) Moul e Silva (2017), (12) Navarro et al. (2007), (13) Rodrigues (2019), (14) Salomão (2016), (15) Santana e Oliveira (2009), (16) Santos (2015), (17) Serra, Freitas e Lira-da-Silva(2013), (18) Souza (2015), (19) Stanski et al. (2016). 


\section{Discussão}

O predomínio de estudos voltados aos alunos do $7^{\circ}$ ano do ensino fundamental II e $2^{\mathrm{a}}$ série do ensino médio deve-se, provavelmente, ao currículo e livros didáticos que retratam o conteúdo sobre plantas predominantemente nestas séries. Há necessidade de desenvolvimento de trabalhos voltados ao ensino de botânica nos anos iniciais do ensino fundamental, pois neste nível os alunos começam a discernir conceitos e a entender a importância da natureza, as relações entre as plantas e o ser humano, havendo assim uma maior possibilidade de sensibilização para as questões ambientais e construção de conhecimentos prévios.

Segundo Santos e Zoch (2018) é nos anos iniciais do fundamental que ocorre a formação de um aluno pesquisador e crítico. O que acontece atualmente é a valorização da alfabetização e letramento apenas em português e matemática, o que dificulta a aquisição de conceitos básicos em ciências que serviriam como conhecimentos prévios para os alunos nos anos finais do ensino fundamental e ensino médio (Santos \& Zoch, 2018).

Segundo a Base Nacional Comum Curricular (BNCC), homologada em 2017, ao ingressar nos anos iniciais do ensino fundamental, o aluno já possui vivências e saberes que devem ser valorizados. Nesta etapa precisa-se oferecer mecanismos para que eles ativem a curiosidade e se envolvam no processo de aprendizagem (Brasil, 2018). No formato educacional proposto pelo documento, os conteúdos vão sendo trabalhados nas séries subsequentes dependendo sempre das etapas anteriores. É necessário um fortalecimento de todos as etapas para que haja a formação integral do aluno. A BNCC está em fase de implantação no ensino fundamental e a partir de 2021 também se iniciará o processo no Ensino Médio. Em um futuro próximo serão necessários estudos para se verificar os impactos, na aprendizagem dos alunos da educação básica, dos currículos baseados na nova diretriz.

Todos os autores analisados, sem exceção, pontuaram que o ensino de botânica da forma como está sendo trabalhado não favorece a aprendizagem. Costa, Duarte e Gama (2019) relatam que os alunos aprendem a botânica de forma superficial e que não conseguem relacionar o conteúdo com o cotidiano. Anjos (2016) defende a utilização de novas metodologias para que a aprendizagem seja significativa. Segundo o autor para minimizar as dificuldades dentro do ensino de botânica deve-se mudar o ensino pautado apenas em livro didático e memorização de conceitos. A tabela 1, compilada a partir do levantamento realizado, lista várias possibilidades de metodologias diferenciadas que podem ser utilizadas pelos professores para trabalhar o conteúdo de Botânica na Educação Básica, importante contribuição desse estudo. Estas metodologias, de modo geral, se contextualizadas adequadamente, podem favorecer a participação ativa do aluno no processo de ensino-aprendizagem tornando a aprendizagem mais significativa.

Barros e Lemos (2016) apontam que a botânica deve ser abordada de forma mais prática, que estimule o aluno a construir seu próprio conhecimento. O aluno não sabe relacionar, por exemplo, que a flor que ele observa em sua casa apresenta as mesmas estruturas florais que ele estuda, teoricamente, na escola. Deve-se, assim, romper as barreiras teóricas e aproximar o estudo das plantas à realidade dos alunos, fazendo com que eles olhem ao seu redor e reconheçam os conceitos que aprenderam na escola.

Várias metodologias compiladas nos diferentes trabalhos analisados (Tabela 1) podem ser plenamente utilizadas, mesmo em escolas carentes em infraestrutura tecnológica adequada, realidade da maioria das escolas públicas brasileiras. Podemos destacar as feiras de ciências, cultivo de plantas através de uma horta, desenhos e aulas de campo/visitas ao entorno da escola (Tabela 1). Estas metodologias podem valorizar e desmistificar o ensino de botânica, favorecendo a participação e motivação do aluno pelo conteúdo. Para tanto, há necessidade de empenho por parte do professor, bem como, engajamento da equipe gestora escolar.

Os jogos interativos e didáticos, e as aulas práticas foram as metodologias mais mencionadas nos diferentes trabalhos analisados (Tabela 1). O lúdico é uma ferramenta didática comprovadamente importante no ensino. Contudo, nem sempre o 
professor tem tempo disponível para criar os jogos. Mas há repositórios de recursos educacionais gratuitos, por exemplo o eduCAPES (https://educapes.capes.gov.br/handle/1884/36898), onde os professores podem acessar e baixar produtos educacionais que atendam às expectativas desejadas. O jogo é um recurso interessante, pois possibilita trabalhar, juntamente com o conteúdo curricular, habilidades como concentração, foco para se alcançar metas, colaboração em equipe, argumentação, entre outros.

No caso de aulas práticas estas não precisam envolver necessariamente laboratórios e equipamentos de alto custo, podem acontecer na própria sala de aula, utilizando materiais que os professores e alunos tragam de casa, ou ainda recicláveis e reutilizáveis. Por exemplo, o professor pode levar para a sala de aula exemplares de plantas e possibilitar ao aluno a identificação e o manuseio das diferentes partes da planta, isso aproxima o aluno do conteúdo trabalhado. As aulas práticas têm a função de instigar a atenção e o interesse dos alunos com relação ao conteúdo trabalhado e auxiliar no desenvolvimento de diversas habilidades (Krasilchik, 2004; Silva et al., 2015).

Segundo Bacich e Moran (2018) é fundamental para o planejamento de aulas a variedade de metodologias e estratégias de ensino, pois além de favorecer a reflexão, pode incentivar o engajamento dos estudantes dentro da proposta. Os mesmos autores ainda pontuam que as pessoas não aprendem da mesma forma e no mesmo ritmo. Quando o professor utiliza estratégias diferentes, fugindo do padrão quadro e giz/livro, a possibilidade de atender às expectativas de aprendizagem é maior, podendo abranger as diferentes habilidades dentro das competências para o ensino de ciências.

Tornar o ensino significativo para o aluno é fazer com que o conhecimento adquirido faça sentido na vida, que ele compreenda conceitos, reflita sobre estes e visualize na prática o que aprendeu. É importante ressaltar que para dar significado ao ensino não existe um único método (como observado nos dados apresentados na Tabela 1). O uso de estratégias variadas, ao longo do ano letivo, pode ser útil para a promoção de um ensino de qualidade (Salomão, 2016). Embora inúmeros autores afirmem que a utilização de metodologias diferenciadas seja válida para a promoção da aprendizagem significativa, Moreira (2011 p. 33) aponta que "a facilitação da aprendizagem significativa depende muito mais de uma postura docente, de uma nova diretriz escolar, do que novas metodologias, mesmo as modernas tecnologias de informação e comunicação", evidenciando que o papel do professor na busca de um ensino de qualidade vai além de apenas usar variados métodos.

De modo geral, os trabalhos analisados elencaram resultados positivos advindos do uso de metodologias diferenciadas (Tabela 2). Os estudos ressaltaram melhorias na participação, engajamento e motivação, e aumento do interesse dos alunos pelas aulas. Podemos afirmar que há certo consenso que ao mudar a dinâmica das aulas, quebrando a rotina "quadro, giz e livro didático", isso melhora a participação dos estudantes, gera emoção e motivação para algo diferente e até então desconhecido. Sabemos que a melhoria da qualidade de ensino na educação envolve múltiplos fatores em variadas escalas, aqui focamos em destacar que no contexto "do chão da sala de aula" pequenas mudanças podem favorecer o processo.

Os resultados apresentados na Tabela 2 também ressaltam a necessidade de envolver os alunos em atividades que promovam o estímulo à curiosidade, que conectem o conteúdo com a realidade e provoquem autonomia. Sendo estes pontos importantes de atenção por parte dos professores.

Uma das dificuldades no ensino e aprendizagem de botânica, apontada pelos diferentes trabalhos, é a falta de relação do conteúdo com a realidade do aluno. Relacionar a botânica com as questões ambientais, com a biodiversidade local e nacional, e abordar o uso das plantas na ornamentação, alimentação e saúde é de extrema relevância para que a aprendizagem se torne significativa, para que o aluno veja que a botânica faz parte da vida.

\section{Considerações Finais}

Diferentes autores apontam que a abordagem do ensino de botânica precisa avançar no contexto real da Escola de Educação Básica para se alcançar o objetivo de aprendizagem e desenvolvimento cognitivo dos alunos. Esta pesquisa mostrou 
que a inserção de metodologias diversificadas facilita o processo de ensino-aprendizagem de botânica gerando significação dos conceitos botânicos e maior familiaridade dos alunos com o conteúdo.

Deve-se assim prezar pela formação de um aluno autônomo, criativo, dinâmico e crítico, o chamado aluno do século XXI (BNCC, 2018). As metodologias diferenciadas podem ser consideradas facilitadoras do processo de construção do conhecimento, uma vez que o aluno não receberá uma lista de conceitos e nomes científicos a decorar, ele terá que abrir os olhos para enxergar a botânica em sua essência e funcionalidade, diminuindo a "cegueira botânica" que vivenciamos na Educação Básica.

Importante salientar que se faz necessário um aprofundamento da aplicabilidade de cada metodologia, evidenciada no presente artigo, nas diferentes etapas de ensino da Educação Básica. A aplicabilidade nas diferentes etapas nos possibilitará uma análise da melhor abordagem do Ensino de Botânica em cada nível, auxiliando na construção e evolução conceitual dos alunos, diminuindo cada vez mais a aversão existente ao ensino-aprendizagem dos conteúdos botânicos.

\section{Referências}

Anjos, C. C. dos. (2016). Contribuições da exposição “descobrindo os segredos das flores do lavrado” como organizador prévio no ensino do conceito de flor (Dissertação de Mestrado, Universidade Estadual de Roraima, Boa Vista, Mestrado Profissional em Ensino de Ciências).

Araújo, G. S. de \& Lemos, J. R. (2016) Confecção e aplicação de modelos didáticos na área de botânica: subsídios metodológicos para o ensino e aprendizagem na educação básica. In: Lemos, J.R.(org.). Botânica na escola: enfoque no processo de ensino e aprendizagem. CRV, 69-85.

Bacich, L. \& Moran, J. (org). (2018). Metodologias ativas para uma educação inovadora. Penso.

Barros, T. De J. C. \& Lemos, J. R. (2016). Construção de um jardim didático como ferramenta educacional para o ensino de botânica em uma escola pública no ensino médio na cidade de Parnaíba, Piauí. In: Lemos, J.R. (org.). Botânica na escola: enfoque no processo de ensino e aprendizagem. CRV, $43-67$.

Bicalho, P. S. S. \& Miranda, S. C. (2015). Biodiversidade do Cerrado: sustentabilidade e saberes Indígenas. Revista Élisée, 4 (1), 53-67. https://www.revista.ueg.br/index.php/elisee/article/view/3589

Bini, E. G. (2019). A horta orgânica como ferramenta no ensino de botânica. (Dissertação de Mestrado Universidade Federal do Mato Grosso, Mestrado Profissional em Ensino de Biologia)

Brasil. (1997) Parâmetros Curriculares Nacionais - PCN. Meio Ambiente e Saúde. Ministério da Educação. Secretaria da Educação Fundamental. Brasília.

Brasil. (2018). Base Nacional Comum Curricular. Educação Infantil e Ensino Fundamental. Ministério da Educação(MEC).

Brito, A. F. (2009). Caça ao tesouro: uma aprendizagem pela descoberta. Actas do X Congresso Internacional Galego-Português de Psicopedagogia. Universidade do Minho, 5535-5544.

Carneiro, J. W. A. (2019). O ensino-aprendizagem de botânica a partir de metodologias ativas com o uso de tecnologias digitais. (Dissertação de Mestrado, Universidade do Estado do Rio Grande do Norte, Mossoró, Mestrado Profissional em Ensino de Biologia)

Carvalho, M. M. (2017). Botânica no Ensino Fundamental II: aplicação de conceitos do movimento CTS por meio de metodologia ativa. (Dissertação de Mestrado Universidade de São Paulo, Lorena, Mestrado em Ciências do Programa de Pós-Graduação em Projetos Educacionais de Ciência)

Costa, E. A., Duarte, R. A. F. \& Gama, J. A. S. (2019). A gamificação da botânica: uma estratégia para a cura da "cegueira botânica". Revista Insignare Scientia, 2 (4), 79-99. https://doi.org/10.36661/2595-4520.2019v2i4.10981

Galvão, T. F. \& Pereira, M. G. (2014). Revisões sistemáticas da literatura: passos para sua elaboração. Epidemiol. Serv. Saúde, 23 (1), $183-184$. https://www.scielo.br/pdf/ress/v23n1/2237-9622-ress-23-01-00183.pdf

Galvão, T. F. ; Pansani, T. S. A. \& Harrad, D. (2015)._Principais itens para relatar Revisões sistemáticas e Meta-análises: A recomendação PRISMA. Epidemiol. Serv. Saúde, 24 (2), 335-342. https://doi.org/10.5123/S1679-49742015000200017

Inada, P. (2016). Ensino de botânica mediado por recursos multimídia: as contribuições de um software de autoria para o ensino dos ciclos reprodutivos dos grupos vegetais. (Tese de Doutorado Universidade Estadual de Maringá, Maringá, Doutorado em Educação para a Ciência e a Matemática).

Katon, G. F.; Towata, N. \& Saito, L. C. (2013). A cegueira botânica e o uso de estratégias para o ensino de botânica. In: III Botânica no Inverno 2013 (org.) LOPEZ A. M. et al. Instituto de Biociências da Universidade de São Paulo, São Paulo.

Krasilchik, M. (2004). Prática de Ensino de Biologia (4a ed). Editora da Universidade de São Paulo.

Kull, C. R. (2018). Problematizar situações de ensino e desenvolver habilidades cognitivas: estudo sobre a importância das folhas para a planta e o ambiente. (Dissertação de Mestrado, Universidade Federal de São Carlos, São Carlos, Mestrado Profissional em Educação).

Lazzari, G., Gonzatti, F., Scopel, J. M. \& Scur, L. (2017). Trilha ecológica: um recurso pedagógico no ensino da Botânica. Scientia cum indústria, 5 (3), 161167. http://dx.doi.org/10.18226/23185279.v5iss3p161 
Matos, G. M. A., Maknamara, M., Matos, E. C. A. \& Prata, A. P. (2015). Recursos didáticos para o ensino de botânica: uma avaliação das produções de estudantes em universidade sergipana. Holos, 31 (5), 213-230. https://doi.org/10.15628/holos.2015.1724

Moreira, M. A. (2011). Aprendizagem Significativa: a teoria e textos complementares. EPU.

Moul, R. A. de M. \& Silva, F. C. L. (2017). A construção de conceitos em botânica a partir de uma sequência didática interativa: proposições para o ensino de Ciências. Revista Exitus, 7 (2), 262-282. https://doi.org/10.24065/2237-9460.2017v7n2ID313

Navarro, D. de F., Silva, S. Z., Marcondes, N. S. P., Volpato, A. M. M., Farago, P. V., Serenato, T., Moreira, E. E. M., Costa, R. G. \& Machado, W. M.(2007). Utilização de plantas medicinais e aromaterapia como ferramenta no ensino fundamental das ciências. Revista Conexão, 3 (1).

Ramos, F. Z. \& Silva, L. H. de A. (2013). Contextualizando o processo de ensino-aprendizagem de botânica. (1 ${ }^{\text {a }}$ ed). Editora Appris.

Rodrigues, F. A. B. (2019). Coleções botânicas e suas contribuições para o ensino de sistemática e morfologia vegetal no ensino médio. (Dissertação de Mestrado, Universidade Estadual do Piauí, Teresina, Mestrado Profissional em Ensino de Biologia).

Salatino, A. \& Buckeridge, M.(2016) "Mas de que te serve saber botânica?". Estudos Avançados, 30 (87), 177- 196.

https://doi.org/10.1590/S0103-40142016.30870011

Salomão, V. M. M. (2016). Horta escolar: temas geradores e os momentos pedagógicos no ensino de ciências. (Dissertação de Mestrado Universidade Federal de Uberlândia, Uberlândia, Mestrado em Ensino de Ciências e Matemática).

Santana, T. A. \& Oliveira, M. A. (2009). Processo de inserção dos mapas conceituais, como recurso didático, no ensino de biologia. Revista Ensenanza de las Ciências. VIII Congreso internacional sobre investigación en la didáctica de las ciencias. p. 1444-1448. Barcelona, 2009.

Santos, I. dos \& Zoch, A. N. (2018). Alfabetização científica: uma sequência didática para o ensino de botânica nos anos iniciais.https://www.upf.br/_uploads/Conteudo/mostra-gaucha produtoseducacionais/resumos2018/ALFA BETIZA\%c3\%87\%c3\%830\%20 CIENT\%c3 \%8d FIC A.pdf.

Santos, M. N. (2015). O ensino de grupos vegetais em diferentes espaços educativos para a promoção da aprendizagem significativa. (Dissertação de Mestrado, Universidade Estadual de Roraima, Boa Vista, Mestrado Profissional em Ensino de Ciências).

Santos, R. L. dos. \& Lemos, J. R. (2016). Concepções dos alunos e professores de uma escola pública da cidade de Parnaíba, Piauí acerca de plantas medicinais. In: Lemos, J.R.(org.). Botânica na escola: enfoque no processo de ensino e aprendizagem. Curitiba: CRV, $43-67$.

Serra, R. M. M., Freitas, H. M. B. \& Lira-DA-Silva, R. M. (2013). O jogo como ferramenta didática para o ensino de botânica. IX Congreso Internacional sobre Investigación En Didáctica De Las Ciencias, 2190-2194.

Silva, A.P.M.; Silva, M. F. S.; Rocha, F. M. R. \& Andrade, I. M. (2015). Aulas práticas como estratégia para o conhecimento em botânica no ensino fundamental. Holos, 31 (8), 68-79. https://doi.org/10.15628/holos.2015.2347

Silva, P. G. P. da \& Cavassan, O. (2005). Avaliação da ordem de atividades didáticas teóricas e de campo no desenvolvimento do conteúdo de botânica da disciplina ciências na $6^{\text {a }}$ série do ensino fundamental. Atas do V Encontro Nacional De Pesquisa Em Educação em Ciências, 5.

Souza, V. W. (2015). Botânica no cotidiano: experiências vivenciadas por alunos do ensino médio. (Dissertação de Mestrado, Universidade Federal de Alagoas, Maceió, Mestrado em Ensino de Ciências e Matemática).

Stanski, C., Luz, C. F. P., Rodrigues, A. R. F. \& Nogueira, M. K. F. S.(2016). Ensino de Botânica no Ensino Fundamental: estudando o pólen por meio de multimodos. Hoehnea, 43 (1), 19-25. https://doi.org/10.1590/2236-8906-34/2015 